\title{
Application of polymer grouting reinforcement technology in the treatment of slope collapse
}

\author{
Zhichao ZHANG ${ }^{1, a}$, Kan LIU ${ }^{1, b}$, Longzhen YE ${ }^{1, c}$ \\ ${ }^{1}$ Key Laboratory of Geohazard Prevention of Hilly Mountains, Ministry of Land and Resources of \\ China, Fujian Fuzhou, 350002, China \\ azhangzhichao0704@126.com, ${ }^{b} 100311216 @ q q . c o m,{ }^{\text {'5 } 526795885 @ q q . c o m ~}$
}

Keywords: High polymer grouting; slope collapse; reinforcement; finite element analysis

\begin{abstract}
Taking into considering of the difficulties and urgency in the treatment of geological hazards such as slope collapse, in light of the deficiencies in previous treatment methods, and also in view that the high polymer material, which has been widely used in geotechnical engineering, possesses the merits of high strength, light weight, high expansibility, short setting time, good durability, easy construction and is water-proof and harmless to the existing structures, the polymer grouting for the treatment of slope collapse is put forward innovatively. It is found that the polymer grouting can handle all kinds of unfavorable conditions in the treatment of slope collapse well. The slope deformation and stability before and after reinforcement with polymer grouting were studied by finite element method. The results indicates that the polymer grouting can deepen the slip circle and increase the sliding path, as a result, it avoids the shallow sliding mode of slope, which leads to the increase of stability and the decrease of slope deformation. After reinforcement, the factor of safety is increased by $35 \%$ and the maximum total displacement is reduced by $34.5 \%$. Hence, the effectiveness of polymer grouting reinforcement technology is preliminarily verified.
\end{abstract}

\section{Introduction of high polymer grouting}

From the 70s in the last century, the high polymer materials has been widely used in geotechnical engineering due to that it possesses the merits of high strength, light weight, high expansibility, short setting time, good durability, easy construction and it is water-proof and harmless to the existing structures. The basic principal of high polymer grouting is to inject two kinds of high polymer materials (such as resin and curing agent) into the structure that needs to be reinforced, then chemical reaction occurs within the two kinds of materials, which instantaneously gives rise to expanded solid material with certain compression, tension, bending and shear strengths. The general implementation process of high polymer grouting is shown in Fig. 1.

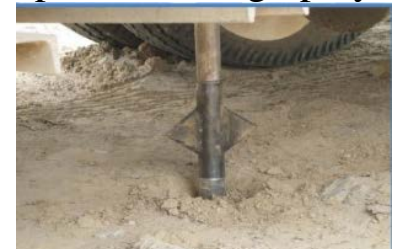

(a) Drilling hole

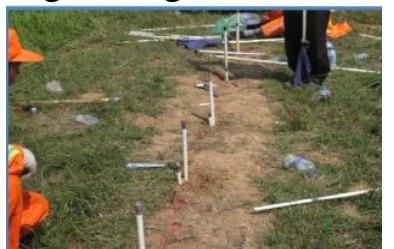

(b) Tube lowering

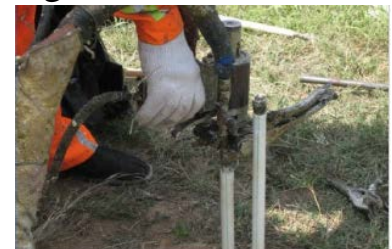

(c) Polymer grouting

Fig. 1 The general process of the polymer grouting reinforcement technology

The reinforcement effect of polymer in the soil includes "polymer pile reinforcement" and “cohesion reinforcement", as seen in Fig. 2. On one hand, the polymer material expands rapidly and drastically when injected into the soil, and then forms the cylindrical or irregular polymer pile that can support loading ${ }^{[1]}$ (see Fig. 2(a)). On the other hand, the polymer material can fill the voids between soil particles and changes into a composite material combined with the soil, which increases the cohesion of soil and improves its strength (see Fig. 2(b)). 


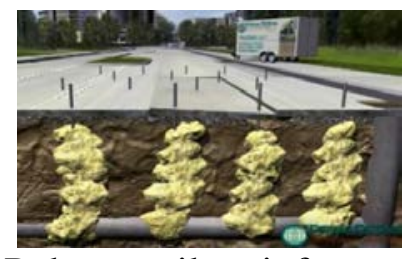

(a) Polymer pile reinforcement

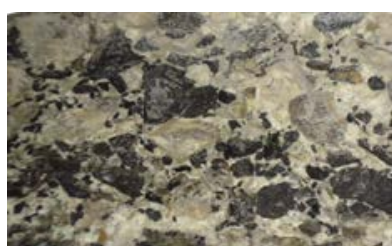

(b) cohesion reinforcement

Fig. 2 Two kinds of reinforcement mechanism of the polymer on soil

The current polymer grouting equipments are also quite flexible. The grouting equipments can be assembled and realized even within a tractor (see Fig. 3), which can fit different engineering scales well. And for some regions with traffic inconvenience, the grouting equipments can even be moved manually to the required place.

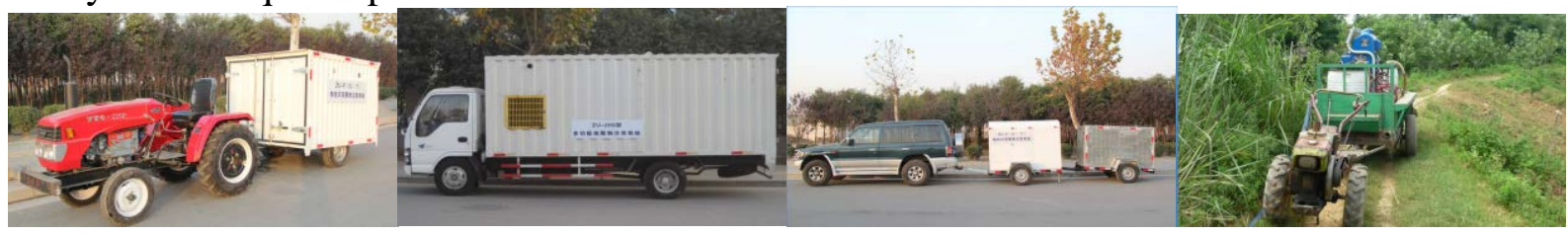

Fig. 3 Equipments for polymer grouting

\section{Applications of high polymer grouting}

Considering the merits of polymer material and the advantages of grouting technology, polymer grouting reinforcement technology has been applied to all kinds of engineering projects, such as subgrade, retaining wall and underground structure ${ }^{[2-5]}$. Kennedy and Woodward et al ${ }^{[6,7]}$ conducted the fatigue tests of railway ballast reinforced with high polymer, the results turn out that the subsidence of railway roadbed is reduced obviously. Erdemgil et $\mathrm{al}^{[8]}$ found that the injected high polymer expanded drastically in the foundation, this reduces the voids of the soil and supports the loading with the soil, which increases the bearing capacity of the foundation. Buzzi and Fityus et $\mathrm{al}^{[9,10]}$ used two kinds of grouting method to study the effect of high polymer on the surrounding soils and the properties of the high polymer materials. Yu et $\mathrm{al}^{[1]}$ introduced the engineering example of high polymer grouting employed in the reinforcement of highway subgrade. The polymer material with high expansibility is injected into the highway subgrade and then inflates significantly, which turns into cylindrical piles, compacts the soil and fills the pore of the soil, hence, the bearing capacity of highway subgrade is increased. Through field loading tests, Valentino et $\mathrm{al}^{[11]}$ found that the expanded high polymer material in the foundation can densify the foundation soil and increase the confining pressure, this in turn enhances the shear strength of foundation soil.

In China, Wang Fuming disclosed the diffusion mechanism of polymer material in the soil and then invented the polymer grouting technology for dam seepage prevention and tunnel gushing water plugging, which has been applied to many significant national engineering projects ${ }^{[12]}$. Wang studied the splitting, compressive, tensile and bending characteristics of high polymer material ${ }^{[13,14]}$

These research results have greatly enhance the application of polymer grouting in geotechnical engineering.

\section{Innovation: application in the treatment of slope collapse}

At present, polymer grouting reinforcement has been applied in building foundation, high speed railway and tunnels etc. ${ }^{[2-5]}$. However, it has not been used in the treatment of slope collapse documentarily yet. The current treatment measures on slope collapse include removal of slip mass, drainage, improvement of slip plane soil, unloading on the slope top and loading on the slope toe and retaining structure etc.. These treatment measures have their own disadvantages:

(1)The removal of slip mass is only applicable to the small soil slopes. Nevertheless, the economical efficiency will be very low and the work load will be remarkable for large slope.

(2)Drainage and improvement of slip plane soil belong to the indirect treatment measures, which 
is not a radical cure for the slope collapse.

(3)Excavation is applied on the slope top to remove additional load, and then surcharge is added on the slope toe. It is aimed to decrease the sliding force and increase the anti-slide force, which in turn enhances the stability of slope. However, it is only applicable to small and medium-sized slope collapse, and the efficiency is low and the earthwork is complex.

(4)For the retaining structures, it is not convenient in construction, and the disturbance due to construction on the existing structures is significant, which may influence the stability of the slope collapse again. What is more, the construction cost is quite high and the construction period is quite long, as a result, it cannot fulfill the urgency of the treatment of geological disaster usually.

(5)Grouting reinforcement is also a common way to control the slope collapse. However, due to the dry-shrinkage characteristic of the conventional cement paste and the adding of water which may affect the stability of slope, the reinforcement of cement grouting is not quite effective. In addition, the long setting time of cement paste would also hamper the application of cement grouting in the treatment of slope collapse because usually the situation of a disaster is critical and needs immediate processing.

Hence, it is necessary to find a high-efficient and instant substitution for the cement grouting so as to react to the slope collapse promptly. As a consequence, through the merits of high polymer materials mentioned above it can be found that the polymer grouting can handle all kinds of unfavorable conditions in the treatment of slope collapse well, as seen in Table 1.

Table 1 The advantages of polymer grouting in slope collapse treatment

\begin{tabular}{|c|c|}
\hline Unfavorable conditions & Solutions of polymer grouting \\
\hline $\begin{array}{l}\text { The disaster is urgent, and the } \\
\text { reinforcement effect should be } \\
\text { immediate. }\end{array}$ & $\begin{array}{l}\text { The high polymer can reach } 90 \% \text { of its final strength } \\
\text { immediately, which shortens the construction time } \\
\text { remarkably. }\end{array}$ \\
\hline $\begin{array}{l}\text { The steep terrain of mountainous area } \\
\text { allows little construction space. }\end{array}$ & $\begin{array}{l}\text { The polymer grouting equipments can be assembled and } \\
\text { realized easily. }\end{array}$ \\
\hline $\begin{array}{l}\text { The stability of the slope is low and } \\
\text { cannot resist much disturbance from } \\
\text { the construction. }\end{array}$ & $\begin{array}{l}\text { The density of the polymer material is quite low, the grouting } \\
\text { equipment is portable and the grouting hole is only } 1 \sim 2 \mathrm{~cm} \text {, } \\
\text { which would not influence the existing structure much. }\end{array}$ \\
\hline $\begin{array}{l}\text { The slip plane of the slope collapse is } \\
\text { the weak plane, and the fracture needs } \\
\text { reinforcement and waterproofing } \\
\text { immediately. }\end{array}$ & $\begin{array}{l}\text { rial } \\
\text { the } \\
\text { c. }\end{array}$ \\
\hline $\begin{array}{l}\text { The economy should } \\
\text { consideration. }\end{array}$ & $\begin{array}{l}\text { outing, the cost } \\
\text { sed on the sam }\end{array}$ \\
\hline
\end{tabular}

Hence, it can be concluded preliminarily that the polymer grouting reinforcement technology may be a perfect solution for the treatment of geological disasters such as slope collapse. Considering that there are large areas of region with intense tectonic activity in China as well as all over the world, once the viability of polymer grouting reinforcement technology on the treatment of slope collapse is validated, it would have a wide application prospect.

\section{Numerical simulation of slope collapse}

The viability of polymer grouting in slope collapse treatment is preliminarily discussed and its application prospect is anticipated reasonably in this paper based on the merits of polymer material, the fundamental performance of grouting equipments and the characteristics of slope collapse. However, the polymer grouting in the treatment of slope collapse is a brand new technology without test of practical engineering. Hence, finite element model of dam slope was built in this paper to study the deformation and stability before and after reinforcement with polymer grouting. It is expected the simulation can provide some validation for the effectiveness of polymer grouting. 


\section{Finite element models of dam slopes}

Finite element models of dam slopes with single-element thickness were built, as seen in Fig. 4. The height of the dam is $100 \mathrm{~m}$, the slope angle is $26.6^{\circ}$ (or slope ratio 1:2). The models are discretized into 78000 solid elements and 78822 nodes. Fig. 4(a) is the dam slope before reinforcement, while Fig. 4(b) is the dam slope after reinforcement with polymer grouting, in which the blue elements on the slope surface and the dam crest with a thickness of $8 \mathrm{~m}$ are the reinforced soil. The bottom boundary of the finite element models are applied with fixed constraint, while the two sides are applied with roller constraint, the axial direction is applied with roller constraint, too.

(a) Before reinforcement with polymer grouting

(b) After reinforcement with polymer grouting Fig. 4 Soil slope model studied

Table 2 indicates the properties of soil before and after reinforcement with polymer grouting. Mohr-Coulomb model is used to simulate the soil, and strength reduction method is applied to study the stability of the dam slope. Considering that the polymer grouting can only increase the cohesion of soil $^{[15]}$, only the cohesion is increased after reinforcement.

Table 2 Material parameters of soil

\begin{tabular}{ccc}
\hline Soil parameters & Before reinforcement & After reinforcement \\
\hline Density $\left(\mathrm{kg} / \mathrm{m}^{3}\right)$ & 2000 & 2000 \\
$c(\mathrm{kPa})$ & 0 & 200 \\
$\varphi\left({ }^{\circ}\right)$ & 26.6 & 26.6 \\
Young's modulus & 80 & 80 \\
$(\mathrm{MPa})$ & 0.3 & 0.3 \\
Poisson's ratio & & \\
\hline
\end{tabular}

\section{Simulation results}

\section{Comparison of factor of safety}

Fig. 5 is the factor of safety before and after reinforcement with polymer grouting by strength reduction method and the slip plane displayed by equivalent strain nephogram at critical state. It turns out that because the soil is cohesionless, the slope exhibits obvious shallow sliding mode and the maximum equivalent strain occurs along the slope surface (Fig. 5(a)). By contrast, the dam slope after reinforcement with polymer grouting changes into deep sliding mode. The factor of safety increases from 1 to 1.35 , and the increment is $35 \%$.

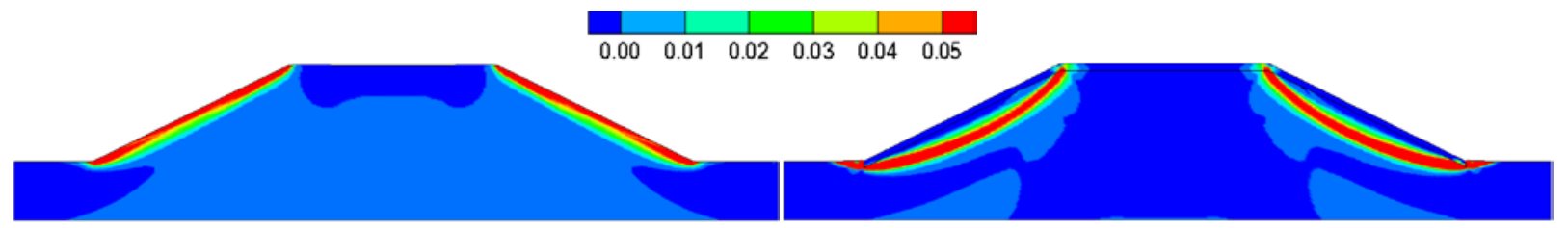

(a) Before reinforcement, FS=1

(b) After reinforcement, FS=1.35

Fig. 5 FS and slip surface of slopes before and after polymer grouting under critical state

\section{Comparison of total displacement}

Fig. 6 is the slope displacement before and after reinforcement with polymer grouting. It can be found that due to the shallow sliding mode of the unreinforced slope, the deformation of the dam slope concentrates near the slope surface (see Fig. 6(a)), and the high-level displacement region 
generally coincides with the high-strain region in Fig. 5 . The maximum displacement is $2.49 \mathrm{~m}$, and the displacement at the dam crest is also relatively large.

In comparison, after reinforcement with polymer grouting, the maximum displacement reduces to $1.63 \mathrm{~m}$, which locates on the dam crest, and the reduction is about $34.5 \%$. The global deformation of the dam slope is obviously lower, too. Hence, it indicates that the polymer grouting can reinforce the slope effectively and restrain the deformation.

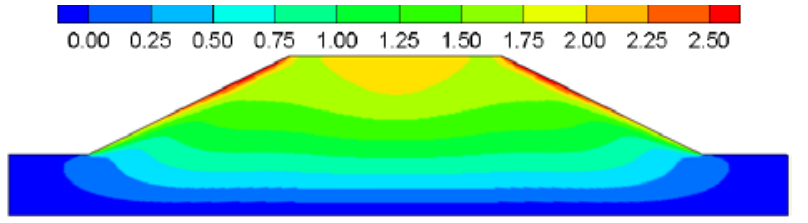

(a) Before reinforcement, displacement $=2.49 \mathrm{~m}$

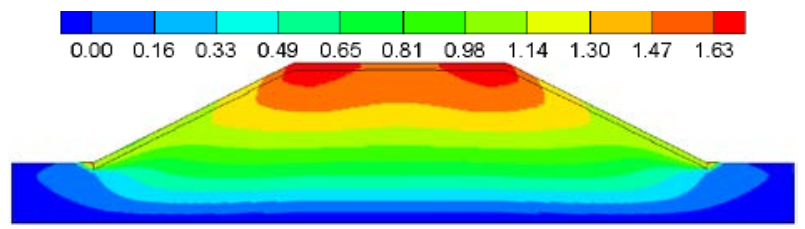

(b) After reinforcement, displacement $=1.63 \mathrm{~m}$ Fig. 6 Comparison of total displacement of slopes before and after polymer grouting

\section{Conclusion}

Taking in into considering of the difficulties and urgency in the treatment of geological hazards such as slope collapse, and in light of the deficiencies in previous treatment methods, and also in view that the high polymer material, which has been widely used in geotechnical engineering, possesses the merits of high strength, light weight, high expansibility, short setting time, good durability, easy construction and is water-proof and harmless to the existing structures, the polymer grouting for the treatment of slope collapse is put forward innovatively in this paper. It avoids the dry-shrinkage and long setting time of the conventional cement grouting. It is found the polymer grouting can handle all kinds of unfavorable conditions in the treatment of slope collapse well.

The slope deformation and stability before and after reinforcement with polymer grouting were studied by finite element method. The results indicate that the reinforcement of polymer grouting on the slope surface can deepen the slip plane, increase the sliding path and as a result, improve the stability. What is more, the deformation of the slope is also reduced obviously, which preliminarily validates the effectiveness of polymer grouting.

The research can promote the application of polymer grouting reinforcement technology in the treatment of slope collapse. Slopes with different dimensions and with layered soils will be studied combined with necessary experimental tests so as to validate this technology more thoroughly.

\section{Acknowledgement}

This research is supported by Natural Science Foundation of Fujian Province (No. 2016J05112) and Key Projects of Science and Technology Department of Fujian Province (2014Y0002)

\section{Reference}

[1] Yu L, Wang R, Skirrow R. The application of polyurethane grout in roadway settlements issues[C]. GeoMontreal 2013. Quebec, Canada: 2013.

[2] Shi Mingsheng, Yu Dongmei, Wang Fuming. Bending Properties of a Polymer Grout [J]. Journal of Materials Science and Engineering, 2010, 28(4): 514-517.

[3] Bodi J, Bodi Z, Scucka J, Martinec P. Polyurethane grouting technologies[M]. Croatia INTECH Open Access Publisher, 2012.

[4] Bian Xuecheng, Cheng Chong, Wang Fuming, et al. Experimental study on dynamic performance and long-term durability of high-speed railway subgrade rehabilitated by polymer injection technology[J]. Chinese Journal of Geotechnical Engineering, 2014, 36(3): 562-568. (in Chinese) 
[5] Xu Jianguo,Wang Fuming,Zhong Yanhui, et al. Stress analysis of polymer diaphragm wall for earth-rock dams under static and dynamic loads [J]. Chinese Journal of Geotechnical Engineering, 2012, 34(9): 1699-1704.

[6] Kennedy J, Woodward P K, Medero G, Banimahd M. Reducing railway track settlement using three-dimensional polyurethane polymer reinforcement of the ballast[J]. Construction and Buliding Materials, 2013, 44: 615-625.

[7] Woodward P K, Kacimi A E, Laghrouche O, et al. Application of polyurethane geocomposites to help maintain track geometry for high-speed ballasted railway tracks [J]. Journal of Zhejiang University- SCIENCE A (Applied Physics \& Engineering), 2012, 13(11): 836-849.

[8] Erdemgil M, Saglam S, Bakir B S. Utilization of highly expansive polymer injection to mitigate seismic foundation failure for existing structures[C]. 8th Pacific Conference on Earthquake Engineering. Singapore: 2007.

[9] Buzzi O, Fityus S, Sasaki Y, Sloan S. Structure and properties of expanding polyurethane foam in the context of foundation remediation in expansive soil[J]. Mechanics of Materials, 2008, 40(12): 1012-1021.

[10]Buzzi O, Fityus S, Sloana S W. Use of expanding polyurethane resin to remediate expansive soil foundations[J]. Canadian Geotechnical Journal, 2010, 47(6): 623-634.

[11] Valentino R, Romeo E, Misra A. Mechanical aspects of micropiles made of reinforced polyurethane resins[J]. Geotechnical and Geological Engineering, 2013, 31(2): 463-478.

[12]Wang Fuming. Research on Polymer Grouting Technology and Equipment for Embankment Reinforcement [R]. Zhengzhou. 2009. (in Chinese)

[13]Shi Mingsheng, Xia Weiyi, Wang Fuming, et al. Experimental study on bond performance between polymer anchorage body and silt [J]. Chinese Journal of Geotechnical Engineering, 2014, 36(4): 724-730.

[14]Shi Mingsheng, Wang Fu-ming, Luo Jing. Compressive strength of polymer grouting material at different temperatures[J]. Journal of Wuhan University of Technlolgy (Material Science Edition), 2010, 25(6): 962-965.

[15]Liu Ping, Liu Hanlong, Xiao Yang, et al. Experimental research on mechanical properties of PFA-reinforced rockfill materials [J]. Rock and Soil Mechanics, 2015, 36(3): 749-754. (in Chinese) 